\title{
FACTORS AFFECTING THE PERFORMANCE OF AQUATIC FEEDS FLAT-DIE PELLETING MACHINE
}

\author{
Abdel Wahab, M.K . ${ }^{1}$ \\ A.M. El Shal ${ }^{2}$ \\ M.A. Tawfik ${ }^{2}$ \\ Y.A. El Hussiny ${ }^{3}$
}

ABSTRACT

The overall goal of the present study is evaluating the performance of a local made flat-die pelleting machine to produce a strong and durable aquatic pelleted feeds with minimum cost. Some operating parameters affecting the performance of machine and pellets quality were studied. The flat-die pelleting machine was evaluated under two values of real hole diameter (4 and $5 \mathrm{~mm}$ ), three different levels of formula particle size (1, 2 and $3 \mathrm{~mm})$, four values of die total thickness $(25,27.5,30$ and $32.5 \mathrm{~mm})$, three levels of roller clearance $(0.5,2$ and $4 \mathrm{~mm})$ and three values of roller teeth width (4, 6 and $8 \mathrm{~mm}$ ) using constant values of die speed of $300 \mathrm{rpm}(4.71 \mathrm{~m} / \mathrm{s})$, average ration moisture content of $15 \%$ (w.b) and hole entry diameter of $9 \mathrm{~mm}$ taking into consideration machine production rate, pellets quality (durability, bulk density) pelleting efficiency, specific energy consumption, economical costs of aquatic feed pellets mass and pellet water stability. From the obtained results, the flatdie pelleting machine could be operate with particle size of $1 \mathrm{~mm}$, die total thickness of $32.5 \mathrm{~mm}$, roller clearance of $2 \mathrm{~mm}$, roller teeth width of $8 \mathrm{~mm}$ and real hole diameter of $4 \mathrm{~mm}$ to achieve the highest values of bulk density of $0.915 \mathrm{~g} / \mathrm{cm} 3$,pellet durability of $95.38 \%$,pelleting efficiency of $95.56 \%$, and pellet water stability of $70 \%$ (up to 4 minutes in water) with values of production rate of $107.10 \mathrm{~kg} / \mathrm{h}$, consumed energy of 97.95 $\mathrm{kW} . \mathrm{h} / \mathrm{Mg}$ and pelleting total cost of $2386.58 \mathrm{L.E.} / \mathrm{Mg}$. Under the same operating conditions, the highest values of bulk density of 0.850 $\mathrm{g} / \mathrm{cm}^{3}$,pellet durability of $91.65 \%$,pelleting efficiency of $94.84 \%$, and pellet water stability of $60 \%$ (up to 4min.) were recorded at real hole diameter of $5 \mathrm{~mm}$ with production rate of $143.65 \mathrm{~kg} / \mathrm{h}$,consumed energy of $58.41 \mathrm{~kW} . \mathrm{h} / \mathrm{Mg}$ and pelleting total cost of $2374.72 \mathrm{L.E.} / \mathrm{Mg}$.

\footnotetext{
${ }^{1}$ Professor, Agric. Eng. Dept., Fac.of Agric., Zagazig Univ.,Egypt.

${ }^{2}$ Lecturer, Agric. Eng. Dept., Fac. of Agric., Zagazig Univ., Egypt.

${ }^{3}$ Post- graduate student, Agric. Eng. Dept., Fac. of Agric .,Zagazig Univ., Egypt.
} 


\section{INTRODUCTION}

he main goal of pelleted feeds manufacturers and nutrienists is
provide a balanced nutritious feeds with a high levels of quality
features in an attempt to maximize nutrient use, utilize the complete or supplemental feed in aquaculture, boost productivity per unit of area, reduce feed wastage and consequently, maintain water quality in either ponds or aquarium in addition to decrease the consumed energy during pelleting operation as well as operation cost. Extrusion agglomeration using a flat die has proved to be a universally acceptable and economic method for compacting any lumpy, long-fibred, powdery, and pasty materials which have not been pre-ground. Therefore, there was a necessity to study the factors affecting the machine performance and pellet quality. Heinemans(1991) recommended a low peripheral die speed of $4-5 \mathrm{~m} . \mathrm{s}^{-1}$ for low bulk density materials, where a large volume of air must be expelled during pelleting. Turner (1995), Franke and Rey (2006) recommended particle size of $0.6-0.8 \mathrm{~mm}$ for good pellet quality. Particle sizes of greater than $1.0 \mathrm{~mm}$ will act as predetermined breaking points in the pellet. Although fine particles produce more durable pellets, fine grinding is undesirable because of increasing cost of production. Grover and Mishra (1996) mentioned that mixture of different particle sizes would give optimum pellet quality because the mixture of particles will make inter-particle bonding with nearly no inter-particle spaces. Thomas et al.(1997) found that high die speed (about $10 \mathrm{~ms}^{-1}$ ) and low die speed (about6-7 $\mathrm{ms}^{-1}$ ) is suggested for small pellets (3-6mm diameter) and large pellets and cubes respectively. In reality, factors related to the feed material characteristics, pre-conditioning processes, and densification equipment variables interact with one another. Therefore, these variables should be optimized using statistical- or mathematicalbased optimization procedures to produce strong and durable densified products. To optimize these variables, in addition to strength and durability, specific energy consumption, production rate, maintenance or production cost would also be considered (Dec, 1999). According to Obernberger and Thek (2004), production of high quality pellets is possible only if the moisture content of the feed is between 8.0 and $12.0 \%$ (w.b.), and water contents above or below this range would lead to 
lower quality pellets. Hence, the main objective of this study is to evaluate, optimize some operating parameters affecting the performance of flat-die pelleting machine and pellets quality during the aquatic feeds production process.

\section{MATERIALS AND METHODS}

The practical experiments were carried out at a private workshop in Zagazig city, Sharkiah Governorate, Egypt.

\section{A-Materials}

\section{-Experimental ration}

The experimental ration prepared by a swinging hammer mill with three different diameters of screen holes to determine three categories of ration particles as 1,2 and $3 \mathrm{~mm}$ in average. The ration formula was mixed in forage mixer with about $15 \%$ moisture of total mass moisture content using the standard method as wet basic(w.b). The composition of the experimental ration is shown in Table (1).

\section{Specifications of flat-die pelleting machine}

The flat-die pelleting machine was fabricated and assembled in a private workshop in Zagazig,Sharkiah governorate, Egypt. The machine mainly consists of the following parts as shown in Fig. (1).

\section{1-Main frame}

Main frame is a base which carrying feeding unit, pressing unit and main electric power motor. It is made from iron steel L-sections with $200 \mathrm{~cm}$ length, $105 \mathrm{~cm}$. width and $98 \mathrm{~mm}$ height.

\section{2- Feeding hopper}

The feeding hopper was made of steel sheet with $2 \mathrm{~mm}$ thickness with $60 \mathrm{~cm}$ length, $30 \mathrm{~cm}$ width and $50 \mathrm{~cm}$ height with maximum capacity of about $10 \mathrm{~kg}$ provided with sliding gate at the bottom to control the ration flow from the hopper to the forming unit.

\section{3- Forming unit}

Forming unit consists of die and rollers. The die is a metal disk made from hard steel (52 carbon) with dimensions of $30 \mathrm{~cm}$ in diameter. Each die profile has working area of $6 \mathrm{~cm}$ width at the middle track surface of the die face. The forming unit consists of two rollers fabricated from hard steel (52 carbon), each roller has a cylindrical shape with dimensions of $100 \mathrm{~mm}$ diameter and $6 \mathrm{~cm}$ in width having corrugated external surface. 
PROCESS ENGINEERING

Table (1): Composition of experimental ration

\begin{tabular}{|l|c|}
\hline \multicolumn{1}{|c|}{ Composition } & Percentage, \% \\
\hline Fish meal & 8 \\
\hline Soy-bean meal & 32.1 \\
\hline Corn(yellow grain) & 31 \\
\hline Wheat bran & 21.33 \\
\hline Fish oil & 2.38 \\
\hline Grain oil & 1.19 \\
\hline Vitamin + min. Premix & 2 \\
\hline Binding agent (starch) & 2 \\
\hline Total & 100 \\
\hline
\end{tabular}

* According to the obtained knowledge from fish feeding research section, central laboratory for aquaculture research, agriculture research center.

The roller constructed and fixed on horizontal axis. The horizontal axis fixed on the top end of main moving shaft, which the movement of rollers has stable motion around horizontal axis.

\section{4- The main shaft}

The main shaft is fixed in a vertical position and constructed on the gearbox which contacted with electric motor to transfer the power and the motion to the die. The main shaft made from hard steel (52 carbon) and there are central hole with diameter of $5 \mathrm{~mm}$ through the shaft length. The maximum length efficiency of the main shaft was $677.92 \mathrm{~mm}$ with different extend diameters. Main shaft is supported by three bearings two conical and flat in shape, the first one is fixed on the die in horizontal position.

\section{5-Cutter knife}

The cutter knife made of stainless steel (37 carbon) with dimensions of 12 $\mathrm{cm}$ in length and $5 \mathrm{~mm}$ in thickness . The cutter blades consists of 4 blades with sharp edges and constructed on the main shaft under the die directly. 


\begin{tabular}{|c|l|}
\hline $\begin{array}{c}\text { Part } \\
\text { No. }\end{array}$ & \multicolumn{1}{|c|}{ Part name } \\
\hline 1 & The main base \\
\hline 2 & Vertical gear box \\
\hline 3 & Oil pump \\
\hline 4 & Outlet chute \\
\hline 5 & Forming die \\
\hline 6 & Bearing \\
\hline 7 & Feeding hopper \\
\hline 8 & Main shaft \\
\hline 9 & The roller \\
\hline 10 & Electric current indicator \\
\hline 11 & Indicating lamp \\
\hline Scale 1:10 Dim.in cm \\
\hline
\end{tabular}

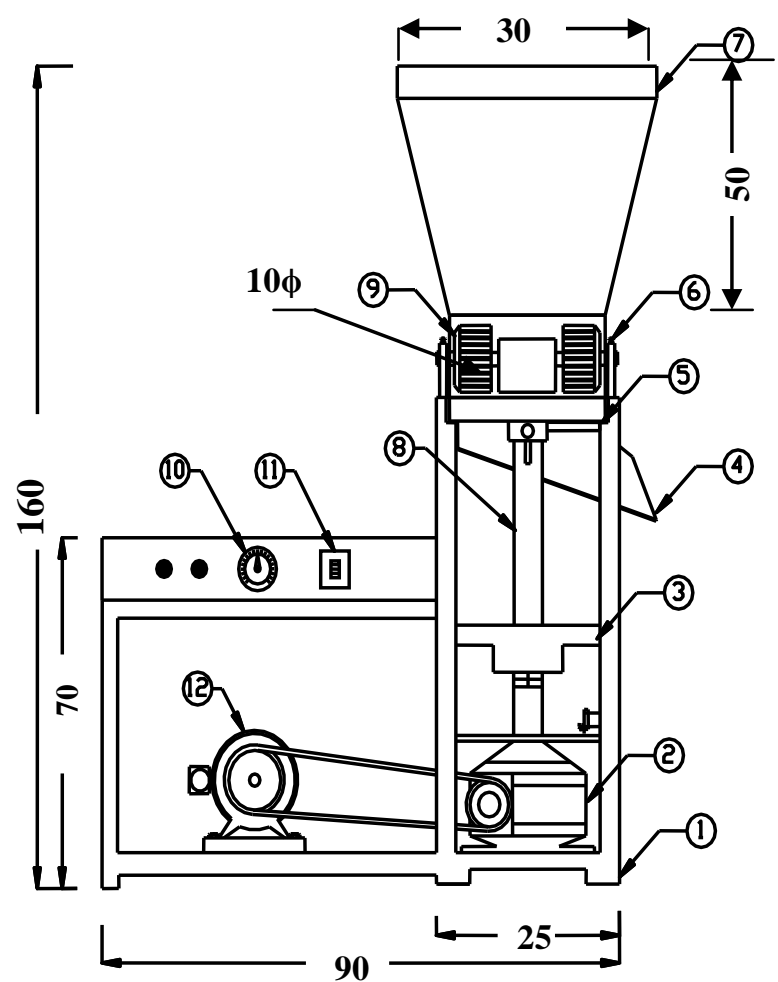

Fig. (1): The flat-die pelleting machine

\section{6- Power unit:}

The main power unit was including motor with rated power of $14.7 \mathrm{~kW}$ at $1400 \mathrm{rpm}$ rotational speed of the motor shaft with $22 \mathrm{~A}$. The speed of motor was reduced at main shaft using 7:1 gearbox. The power transmitted from the motor shaft to gear box through a pulley $(8 \mathrm{~cm}$ in diameter) using three $\mathrm{V}$ belts.

\section{B-Methods}

Experiments were carried out to evaluate a local made flat-die pelleting machine under constant die speed of $300 \mathrm{rpm}(4.71 \mathrm{~m} / \mathrm{s})$, feeding of $5 \mathrm{~kg} /$ treatment, ration moisture content of $15 \%$ (w.b) and hole entry diameter of $9 \mathrm{~mm}$ to optimize some operating parameters affecting the machine performance and pellets quality, these parameters were:

1- Two real hole diameters (4 and $5 \mathrm{~mm}$ ).

2- Three formula particle sizes (1,2 and $3 \mathrm{~mm})$.

3- Four die total thickness (25, 27.5, 30 and 32.5mm).

4- Three different levels of roller clearance $(0.5,2$ and $4 \mathrm{~mm})$. 
5- Three different values of roller teeth width (4, 6 and $8 \mathrm{~mm})$.

Evaluation of the above mentioned parameters was taking into consideration the following indicators:

\section{1- Production rate}

Production rate $=\frac{W_{P}}{T} \times 3.6$

Where: Wp: pellets mass $(\mathrm{g})$

$\mathrm{T}$ : consumed time (s)

\section{2-Pelleting efficiency}

Pelleting efficiency $(\%)=\frac{W p}{W m} \times 100$

Where: $\mathrm{W}_{\mathrm{p}}$ : pellets yield mass $(\mathrm{g}) . \quad \mathrm{W}_{\mathrm{m}}$ : ration sample mass $(\mathrm{g})$.

\section{3- Pellet durability:}

The durability of pellets was determined according to ASAE standard (1996). Since pellets were sieved on the appropriate sieve to remove fines. A sample mass of about $500 \mathrm{~g}$ placed in the tumbling box device for tumbling up to $10 \mathrm{~min}$, the sample will be removed, sieved and the percent of the whole pellets calculated as follows:

Durability $(\%)=\frac{W a}{W b} \times 100$

Where: Wa: pellets mass after tumbling $(\mathrm{g})$. Wb: pellets mass before tumbling $(\mathrm{g})$

\section{4-Pellets bulk density}

Bulk density $\left(\mathrm{g} / \mathrm{cm}^{3}\right)=\frac{W d}{V d}$

Where: $\mathrm{W}_{\mathrm{d}}$ : pellets sample mass $(\mathrm{g}) . \quad \mathrm{V}_{\mathrm{d}}$ : pellets sample volume $\left(\mathrm{cm}^{3}\right)$.

\section{5- Total consumed power}

The consumed power was calculated according to the following equation (Ibrahim, 1982).

Total consumed power, $(k W)=\frac{\sqrt{3} I V \eta \cos \theta}{1000}$

Where:

I : Line current strength, Amperes. 
$\mathrm{V}$ : Potential difference (Voltage) being equal to $380 \mathrm{~V}$.

$\operatorname{Cos} \theta$ : Power factor (being equal to 0.84 ).

$\sqrt{3}$ : Coefficient current three phase (being equal 1.73).

$\eta \quad$ : Mechanical efficiency assumed (90\%).

\section{6- Specific consumption energy}

Consumed power $(k W)$

Specific consumption energy $(k W . h / M g)=$

Machine productivity $(\mathrm{kg} / \mathrm{h})$

\section{7- Total Cost per mass unit:}

Total cost (L.E/h)

Cost per mass unit of production $(L \cdot E / M g)=$

Machine productivity $(\mathrm{Mg} / \mathrm{h})$

The machine cost was determined (according to the prices at the period of experiment) by using the following formula (Awady et al., 2003):

$$
C=\frac{p}{h}\left(\frac{1}{a}+\frac{i}{2}+t+r\right)+(W . e)+\frac{m}{144}
$$

Where:

C : Machine hourly cost, L.E./h.

$P$ : Price of machine, L.E.

$\mathrm{h}$ : Yearly working hours.

a : Life expectancy of the machine, year.

i : Interest rate/year .

$\mathrm{t}$ : Taxes and over heads ratio, $\%$.

$\mathrm{R}$ : Repairs and maintenance ratio, $\%$.

$\mathrm{W}$ : Power of motor, $\mathrm{kW}$.

e : Hourly cost/kW.h.

$\mathrm{m}$ : The monthly average wage, L.E.

144: The monthly average working hours.

\section{8-Pellets water stability}

Pellets water stability was determined as a period of pellet stability in water using glass filling up with water. Sample mass of pellets placed inside the glass for time that pellets start to disintegrate, then the percentage of persevered pellets during the period (in minutes) was calculated. 


\section{RESULTS AND DISCUSSION}

\section{1- Effect of some operating parameters on production rate}

Fig. (2) showed that, as the particle size increased from 1 to $3 \mathrm{~mm}$, the highest values of production rate decreased from 151.8 to $148.8 \mathrm{~kg} / \mathrm{h}$ and 187.2 to $184.8 \mathrm{~kg} / \mathrm{h}$ at real hole diameters of 4 and $5 \mathrm{~mm}$ respectively. The little decrease could be due to the large particles accepted less moisture, so the lubricant effect will disappear, that means less productivity. It is also observed that, the highest production rate of $151.8 \mathrm{~kg} / \mathrm{h}$ at real diameter of $4 \mathrm{~mm}$ increased to $187.2 \mathrm{~kg} / \mathrm{h}$ at real hole diameter of $5 \mathrm{~mm}$. This increase may be due to the increasing of the output area that make the mass flow of ration to get out from die holes at less time. The obtained data showed that, by increasing the die total thickness from 25 to $32.5 \mathrm{~mm}$, the highest values of production rate at particle size of $1 \mathrm{~mm}$ decreased from 151.8 to $137.4 \mathrm{~kg} / \mathrm{h}$ and 187.2 to $172.8 \mathrm{~kg} / \mathrm{h}$ for real hole diameters of 4 and $5 \mathrm{~mm}$ respectively. This decrease could be due to the compressed ration will pass through a long distance inside the forming die that means increasing in the treatment consumed time. The results indicated that, the production rate decreased by increasing the roller clearance from 0.5 to $4 \mathrm{~mm}$ as a general trend under the whole operating parameters. This decrease may attributed to the decrease in the compression force for the movement of the mixture in die holes which leads to a great reduce in mass flow rate. It is noticed that, the production rate increased by increasing the roller teeth width from 4 to $6 \mathrm{~mm}$, but the increase of the teeth width more than $6 \mathrm{~mm}$, production rate tend to decrease. This could be explained as the increase of space between the roller teeth may be increase the pressure inside the clearance between roller and die, but increasing roller teeth more than $6 \mathrm{~mm}$ may caused more compaction for the ration, that means less productivity. The optimum values of production rate which were recorded at the highest values of pelleting efficiency, pellet bulk density, durability and water stability.

\section{2- Effect of some operating parameters on pellet bulk density}

Pellet bulk density considered as the major aquatic feed controller. Fig. (3) showed that, as the particle size increased from 1 to $3 \mathrm{~mm}$, the highest values of pellet bulk density decreased from 0.915 to $0.722 \mathrm{~g} / \mathrm{cm}^{3}$ and 0.830 to $0.643 \mathrm{~g} / \mathrm{cm}^{3}$ at real hole diameters of 4 and $5 \mathrm{~mm}$ respectively. 

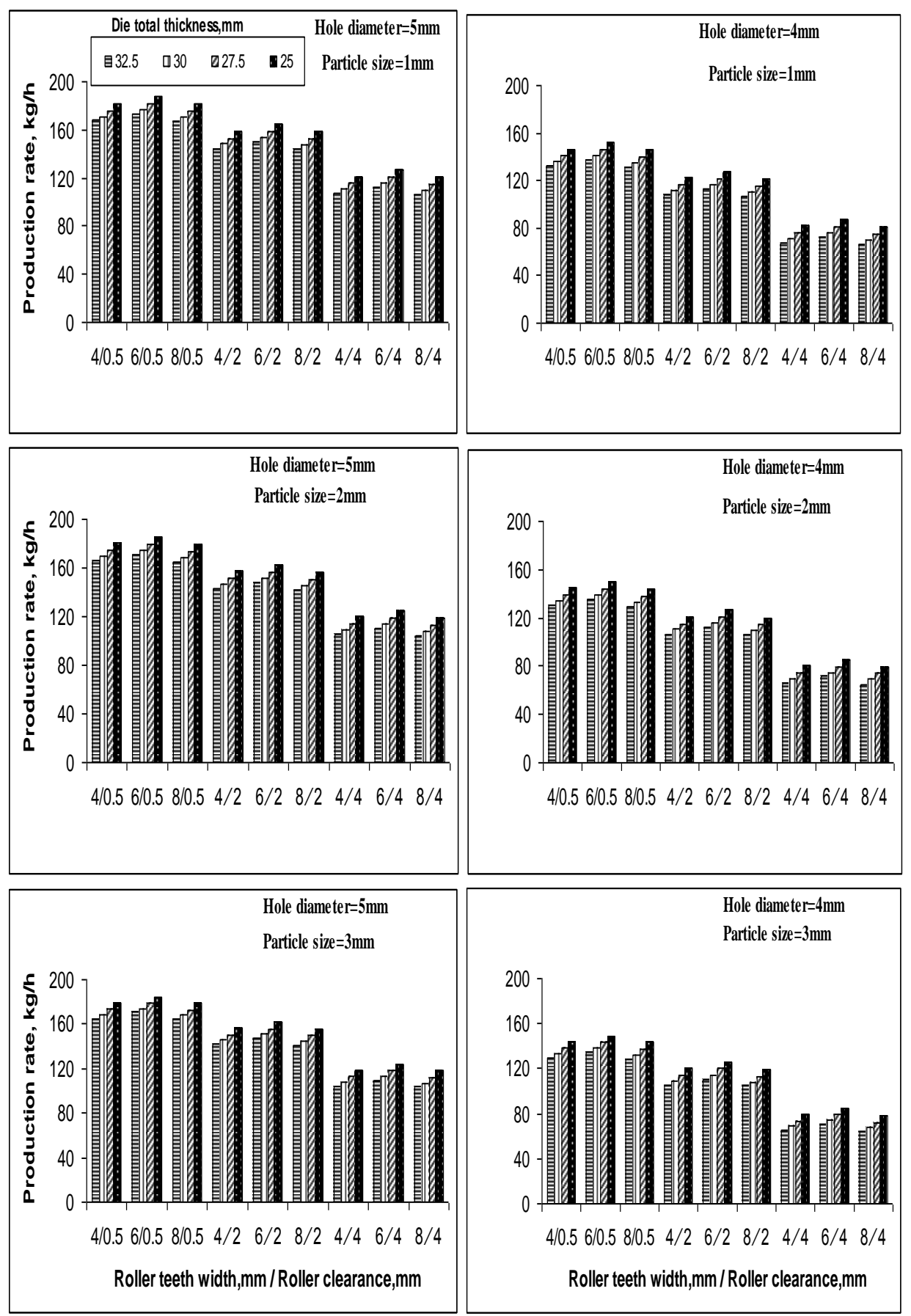

Fig.(2): Effect of some operating parameters on production rate. 
This decrease could be due to the large inter-particles spaces between large particles resulting in reducing pellet bulk density. The results also showed that, the highest pellet bulk density of $0.915 \mathrm{~g} / \mathrm{cm}^{3}$ at real diameter of $4 \mathrm{~mm}$ decreased to $0.830 \mathrm{~g} / \mathrm{cm}^{3}$ at real hole diameter of $5 \mathrm{~mm}$. The decrease of pellet bulk density by increasing real hole diameter could be due to the reduce of compaction level inside the die hole that is mean decreasing of pellets volume with constant mass. The obtained data indicated that, the increase of die total thickness from 25 to $32.5 \mathrm{~mm}$ was followed with an increase in pellet bulk density from 0.714 to $0.915 \mathrm{~g} / \mathrm{cm}^{3}$ and 0.629 to $0.830 \mathrm{~g} / \mathrm{cm}^{3}$ for real hole diameters of 4 and $5 \mathrm{~mm}$ respectively at particle size of $1 \mathrm{~mm}$, clearance of $2 \mathrm{~mm}$ and teeth width of $8 \mathrm{~mm}$. This increase could be attributed to the increase in materials retention time in die holes that mean more compaction to the ration granules. It was also found that, pellet bulk density decreased by increasing the roller clearance from 0.5 to $4 \mathrm{~mm}$. This is may be due to the high accumulation of the mixed ration at the larger clearance, which means the ration tend to escape from the gap between the roller and forming die. It is noticed that, pellet bulk density increases as the roller teeth width increased from 4 to $8 \mathrm{~mm}$. This increase may be due to the decrease of inter-teeth spaces, that means more compression for ration. The results stated that, the optimum values of pellet bulk density were 0.915 and $0.850 \mathrm{~g} / \mathrm{cm}^{3}$ for real hole diameters of 4 and $5 \mathrm{~mm}$ respectively, at particle size of $1 \mathrm{~mm}$, die total thickness of $32.5 \mathrm{~mm}$, roller clearance of $2 \mathrm{~mm}$ and roller teeth width of $8 \mathrm{~mm}$.

\section{3- Effect of some operating parameters on pellet durability}

In the feed industry, high durability means high quality. Fig.(4) showed that, the highest values of pellet durability decreased from 95.38 to $82.65 \%$ and 91.65 to $78.65 \%$ at real hole diameters of 4 and5mm respectively, at particle size of $1 \mathrm{~mm}$. This may be due to the large spaces among the larger particles which caused a weak bonds and consequently, decreasing the pellets resistance for broking. Whereas, the highest pellet durability of $95.38 \%$ at real diameter of $4 \mathrm{~mm}$ decreased to $91.65 \%$ at real hole diameter of $5 \mathrm{~mm}$ at particle size of $1 \mathrm{~mm}$. This decrease may due to the increase of output area which (the hole) caused a reduce in the pressure inside it, that means a low level of compaction and increasing air cells between the granules resulting in decreasing pellet resistance for 

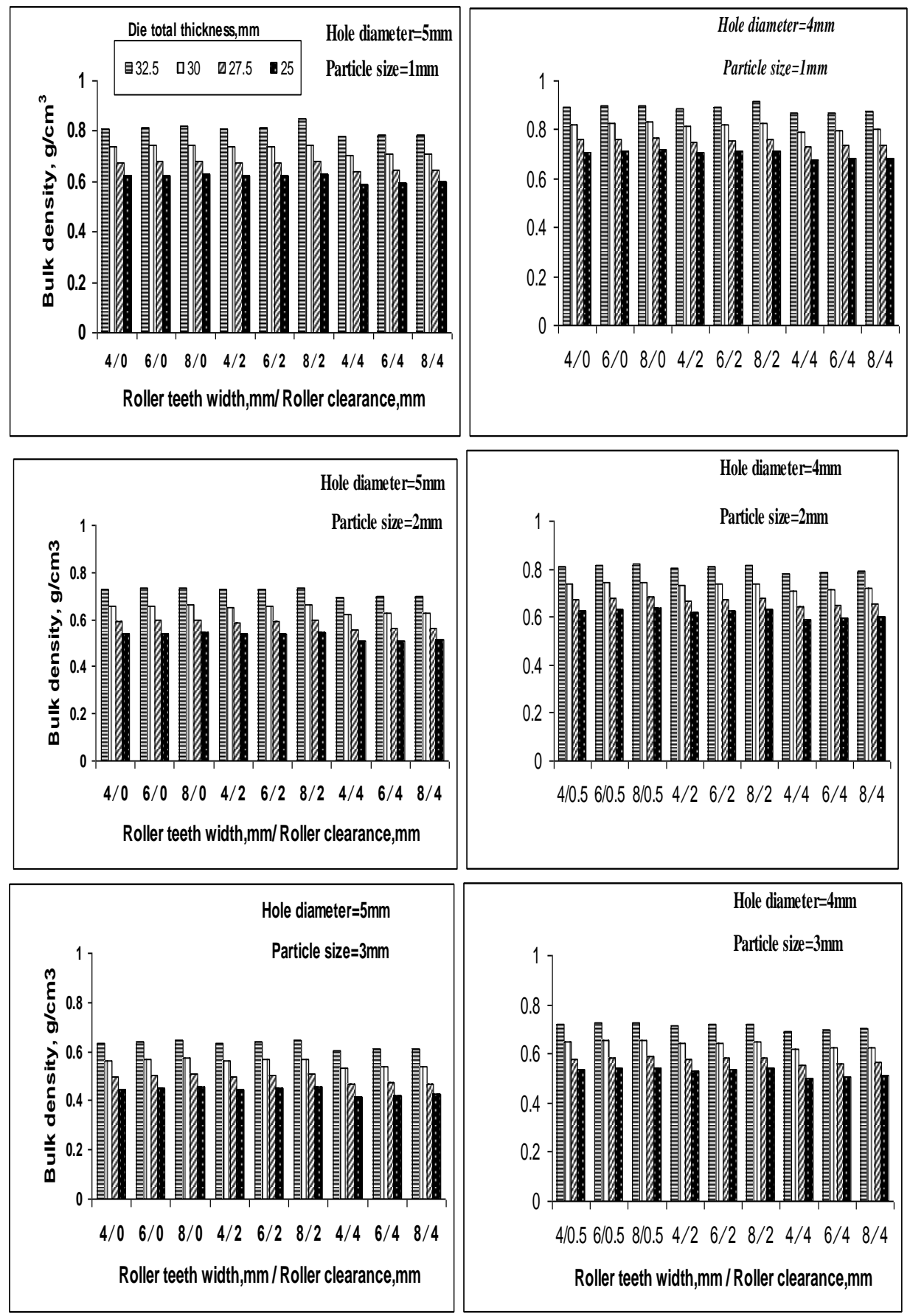

Fig.(3): Effect of some operating parameters_on bulk density. 
cracking. Fig.(4) showed that, the increase of die total thickness from 25 to $32.5 \mathrm{~mm}$ was followed with a decrease in pellet durability from85.61 to $95.38 \%$ and 78.96 to $91.65 \%$ for real hole diameters of 4 and $5 \mathrm{~mm}$ respectively, at particle size of $1 \mathrm{~mm}$,clearance of $2 \mathrm{~mm}$ and teeth width of $8 \mathrm{~mm}$.This decrease may due to the increase of retention time in the real hole and that increase the strength of pellet. It was also observed an increase in pellet durability by increasing the roller clearance from 0.5 to $2 \mathrm{~mm}$, but increasing the clearance to $4 \mathrm{~mm}$, will reduce the capability of roller to compress the accumulated ration in the roller gap. Results show that, increasing the roller teeth width from 4 to $8 \mathrm{~mm}$ will increase pellet durability. This is may be due to the decrease of area between roller teeth, resulting in increasing the pressure inside hole. It is clear that, the highest values of pellet durability were 95.38 and $91.65 \%$ for real hole diameters of 4 and $5 \mathrm{~mm}$ respectively, at particle size of $1 \mathrm{~mm}$, die total thickness of $32.5 \mathrm{~mm}$, roller clearance of $2 \mathrm{~mm}$ and roller teeth width of $8 \mathrm{~mm}$.

\section{4- Effect of some operating parameters on pellet water stability}

Pellet water stability is an important indicator for pellet quality. Fig(5) showed that, the percentage of pellet water stability decreases by increasing the particle size from 1 to $3 \mathrm{~mm}$. This an expected because the large particles will permit water to penetrate the granules of pellet and reduce the pellet stability period. It was also noticed that, the increase of real hole diameter from 4 to $5 \mathrm{~mm}$ was followed with a decrease in the percentage of remained pellet in water after four minutes from70 and 50\% at particle size of $1 \mathrm{~mm}$, die total thickness of 32.5 ,clearance of $2 \mathrm{~mm}$ and teeth width of $8 \mathrm{~mm}$. The obtained results showed that, pellet water stability increased by increasing die total thickness and roller teeth width. This is could be due to the increase of retention time of ration inside die hole at large thickness of die $(32.5 \mathrm{~mm})$ and the high compaction at the wider roller teeth of $8 \mathrm{~mm}$. The obtained result showed that increasing roller clearance from 0.5 to $2 \mathrm{~mm}$ would increase pellets durability so that, long period for pellet stability ,but any further increase in roller clearance, caused a reduce in the stable period. The best percentage of pellet water stability were $70 \%$ and $60 \%$ (up to 4 minutes) for real hole diameters of 4 and $5 \mathrm{~mm}$ respectively, at particle size of $1 \mathrm{~mm}$, die total thickness of 32.5 $\mathrm{mm}$, roller clearance of $2 \mathrm{~mm}$ and roller teeth width of $8 \mathrm{~mm}$. 

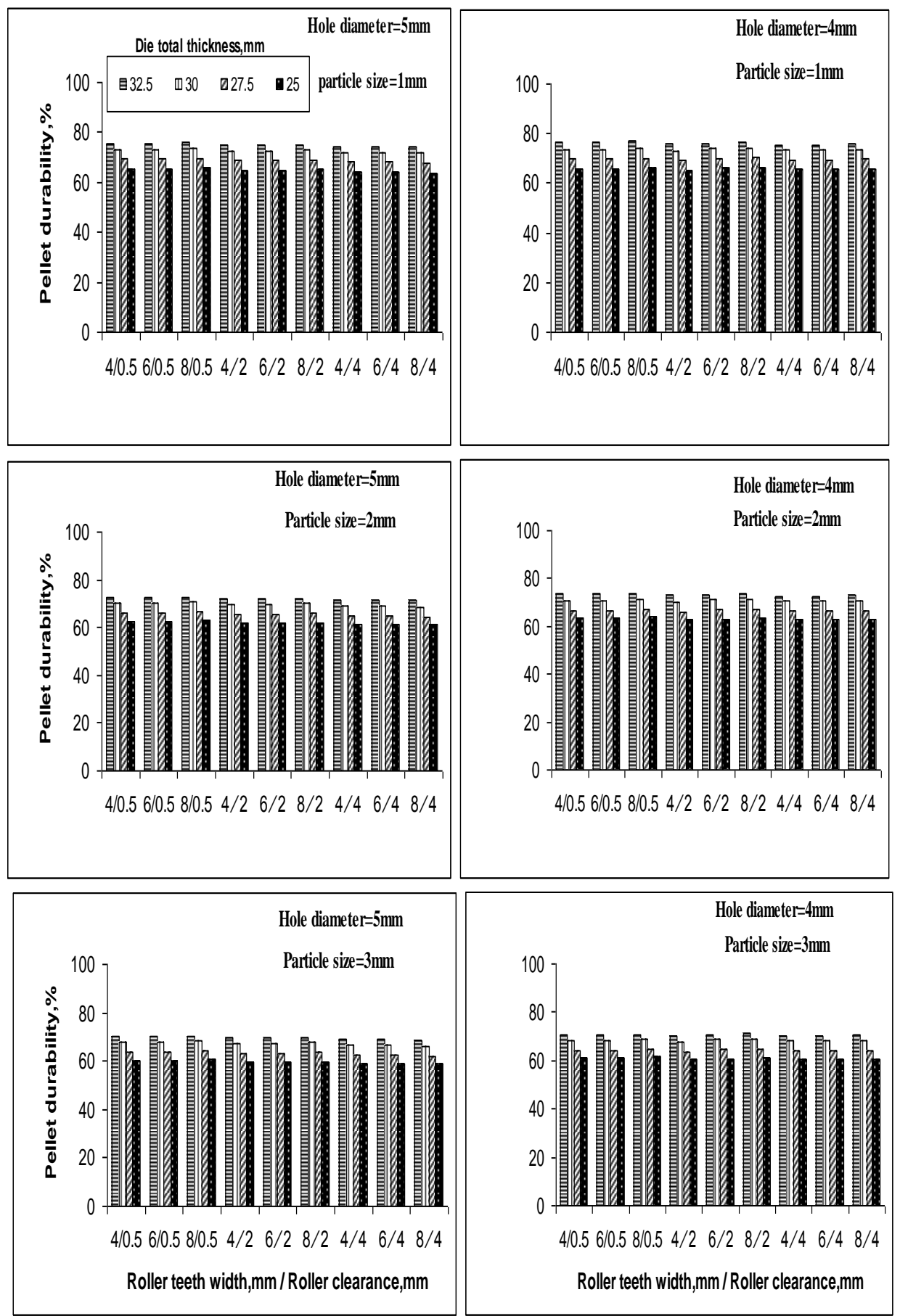

Fig.(4): Effect of some operating parameters on pellet durability. 

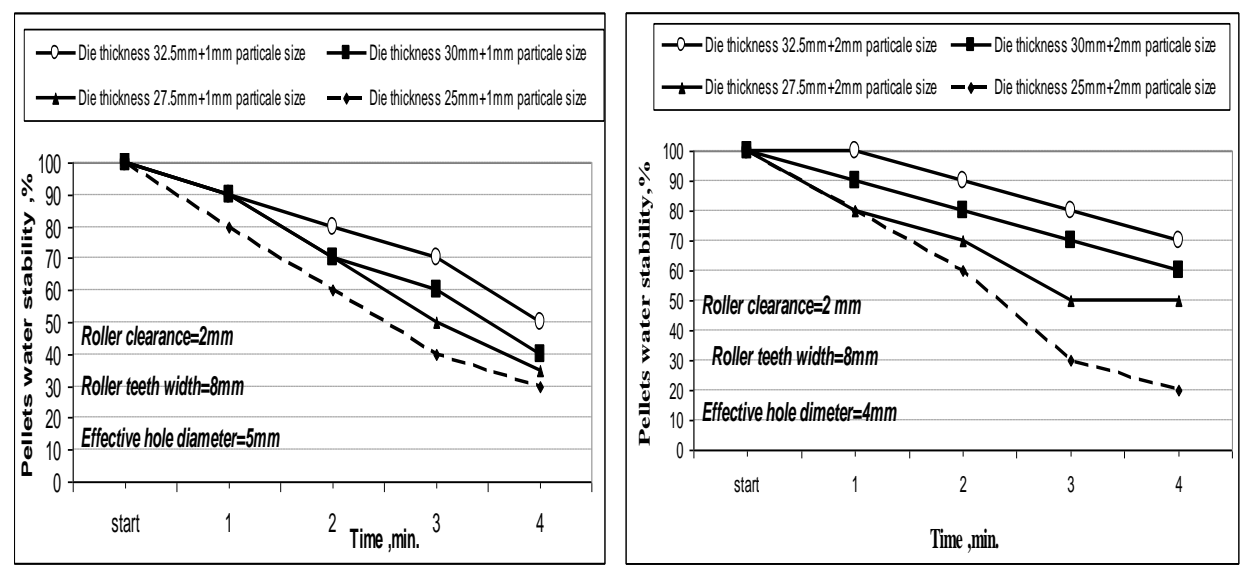

Fig. (5): Effect of some operating parameters on pellet water stability.

\section{5- Effect of some operating parameters on pelleting efficiency}

Particle size is an important influencer of pelleting efficiency. Fig.(6) illustrated that ,by increasing the particle size from 1 to $3 \mathrm{~mm}$, the best values of pelleting efficiency decreased from 95.65 to $93.26 \%$ and 94.84 to $89.98 \%$ for real hole diameters of 4 and $5 \mathrm{~mm}$ respectively . This could be due to the large inter-particles spaces between large particles resulting in increasing the deformation of the produced pellets. The same trend was observed with the real hole diameter. This decrease could be due to the decrease of the compaction of the ration at the same particle size of formula in the larger diameter holes. The obtained results showed that, the increase of die total thickness from 25 to $32.5 \mathrm{~mm}$ was followed with an increase in pellet efficiency from 88.37 to $95.65 \%$ and 85.49 to $94.84 \%$ for real hole diameters of 4 and $5 \mathrm{~mm}$ respectively, at particle size of $1 \mathrm{~mm}$, clearance of $2 \mathrm{~mm}$ and teeth width of $8 \mathrm{~mm}$. This increase could be due to the retention time of ration inside the die holes resulting in increasing the compaction of pellets. Fig.(5) showed that ,by increasing the roller clearance from 0.5 to $2 \mathrm{~mm}$ the pelleting efficiency increased ,but the opposite trend was observed at clearance of $4 \mathrm{~mm}$. The ration may accumulate in large clearance, resulting in low durable pellet. It noticed also that, the pelleting efficiency increases as the teeth width increased from 4 to $8 \mathrm{~mm}$. This increase may due to the increase of durable pellets. Finally, The obtained results revealed that, the highest values of pelleting efficiency of 95.56 and $94.84 \%$ for real hole diameter of 4 and $5 \mathrm{~mm}$ 

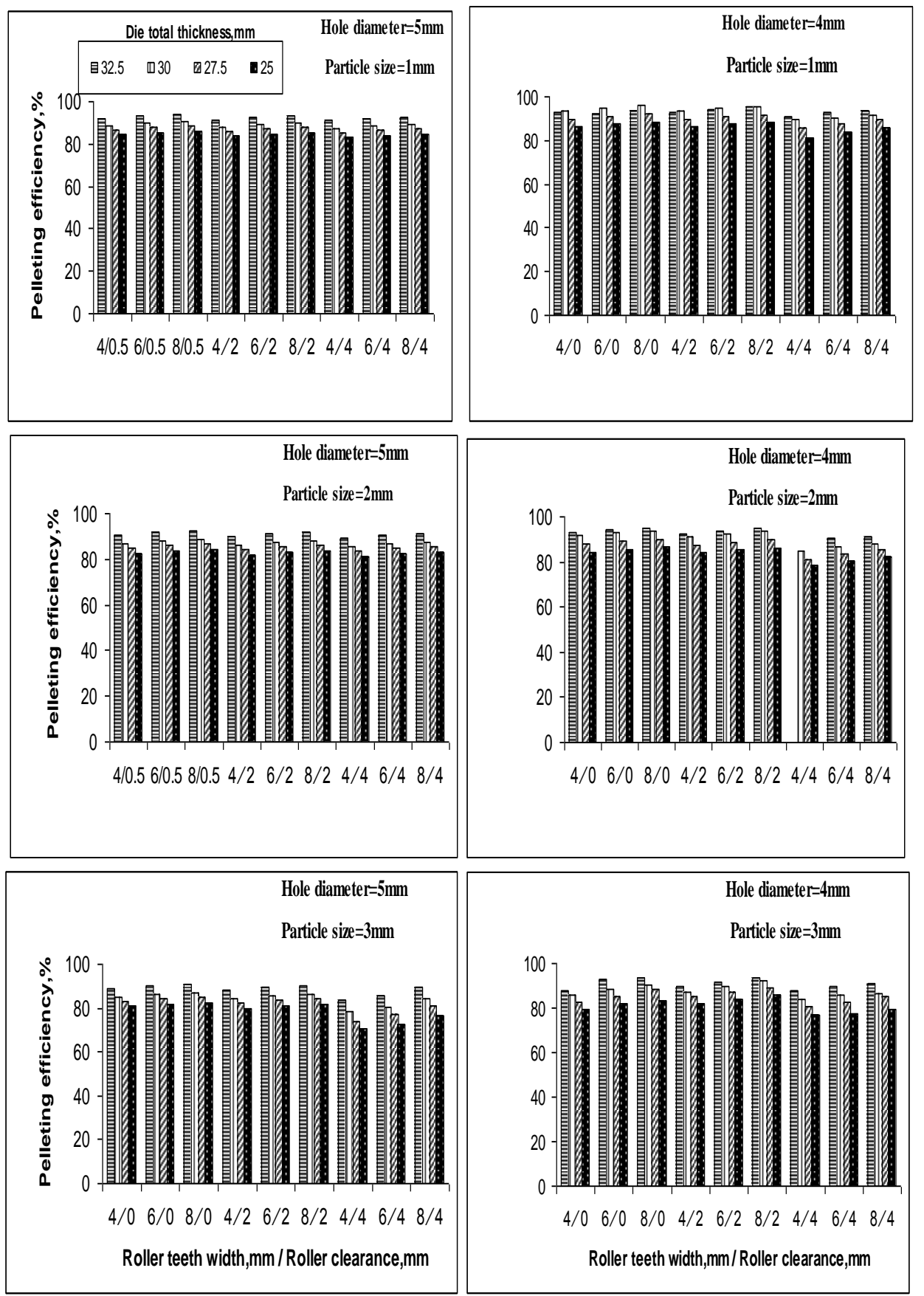

Fig.(6): Effect of some operating parameters on pelleting efficiency. 
respectively, were recorded at particle size of $1 \mathrm{~mm}$, die total thickness of $32.5 \mathrm{~mm}$, roller clearance of $2 \mathrm{~mm}$ and roller teeth width of $8 \mathrm{~mm}$.

\section{6- Effect of some operating parameters on power requirement}

The aquatic feed pellets energy requirements depends theoretically on consumed power and production rate of the pelleting machine. Fig.(6) showed that, increasing the particle size from 1 to $3 \mathrm{~mm}$, the energy requirement decreased from 97.95 to $102.97 \mathrm{~kW} . \mathrm{h} / \mathrm{Mg}$ and 58.41 to 61.17 $\mathrm{kW} . \mathrm{h} / \mathrm{Mg}$ for real hole diameters of 4 and $5 \mathrm{~mm}$ respectively at die total thickness of $32.5 \mathrm{~mm}$, roller clearance of $2 \mathrm{~mm}$ and roller teeth width of $8 \mathrm{~mm}$.Using large particle size may increase the friction inside the die hole resulting in reducing the production rate and increase the power requirement. At the same conditions, the energy requirement decreases from 97.95 to $58.41 \mathrm{~kW} . \mathrm{h} / \mathrm{Mg}$ as the real hole diameter increased from 4 to5mm. This decreased could be attributed to the high increase in production rate .It was noticed also that, the increase of die total thickness from 25 to $32.5 \mathrm{~mm}$ would increase the energy requirement from 48.48 to $97.95 \mathrm{~kW} . \mathrm{h} / \mathrm{Mg}$ and 23.98 to $58.41 \mathrm{~kW} . \mathrm{h} / \mathrm{Mg}$ for real hole diameters of 4 and $5 \mathrm{~mm}$ respectively, at particle size of $1 \mathrm{~mm}$, roller clearance of $2 \mathrm{~mm}$ and roller teeth width of $8 \mathrm{~mm}$ for real hole diameters of 4 and5mm respectively, at die total thickness of $32.5 \mathrm{~mm}$, roller clearance of $2 \mathrm{~mm}$ and roller teeth width of $8 \mathrm{~mm}$. This may be due to the increase of the retention time of the compressed ration in die hole, resulting in decreasing the productivity. The results showed that, increasing roller clearance from 0.5 to $4 \mathrm{~mm}$ may cause a high accumulation of ration in gap between the roller and die resulting in increasing of consumed power. Fig.(6) indicated that, the increase of teeth width from 4 to $6 \mathrm{~mm}$ followed by a decrease in the required energy, but increasing of teeth width more than $6 \mathrm{~mm}$, the required energy tend to increase. This may be due to the decrease of production rate. The optimum values of energy requirement of 97.95 and $58.41 \mathrm{~kW} . \mathrm{h} / \mathrm{Mg}$ for real hole diameters of 4 and $5 \mathrm{~mm}$ respectively, were recorded at the highest values of bulk density, pellet durability and pelleting efficiency using particle size of $1 \mathrm{~mm}$, die total thickness of $32.5 \mathrm{~mm}$, roller clearance of $2 \mathrm{~mm}$ and roller teeth width of $8 \mathrm{~mm}$. 

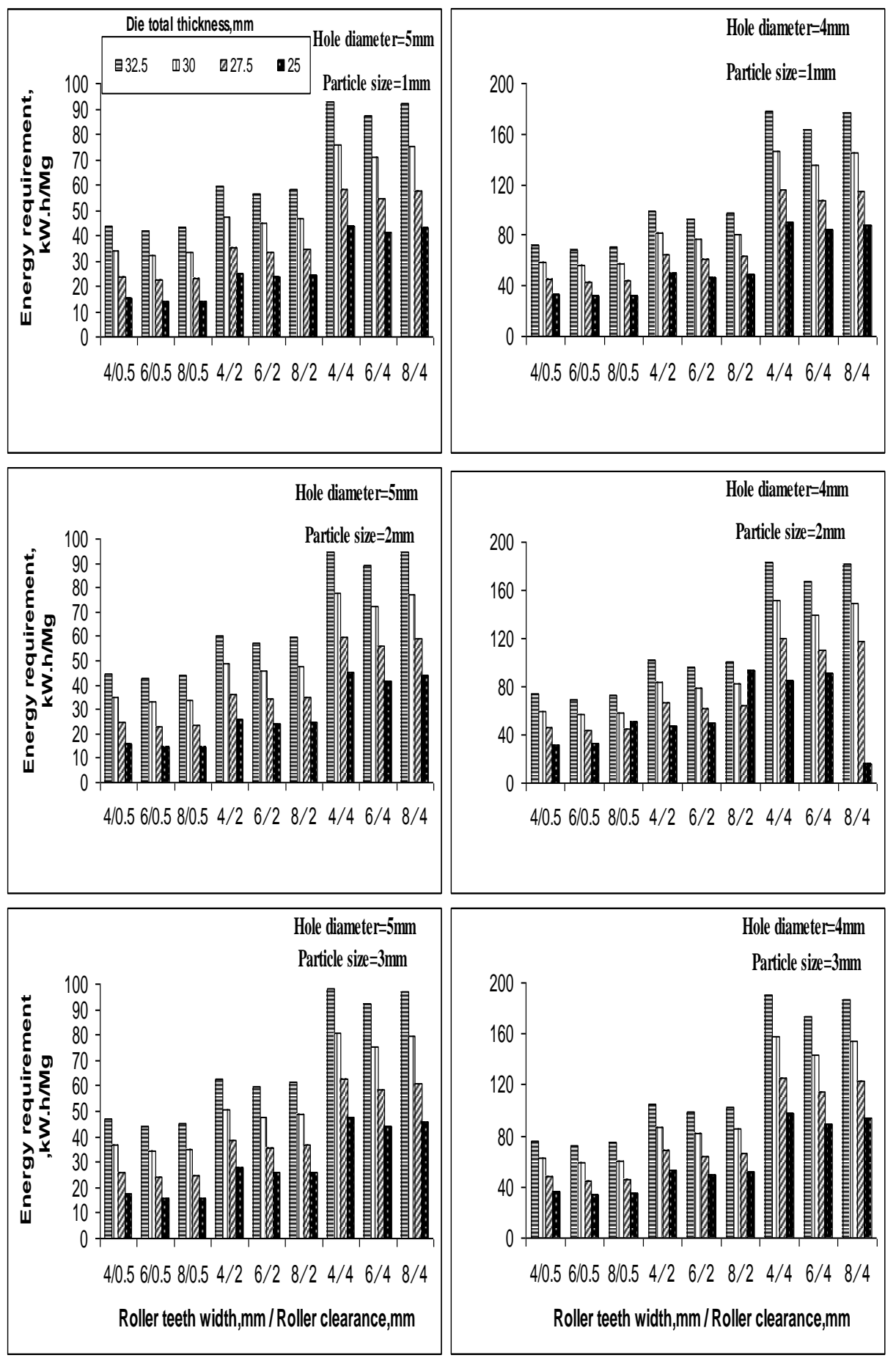

Fig.(7): Effect of some operating parameters on energy requirement. 


\section{7- Effect some operating parameters on cost per mass unit}

Fig.(7) illustrated that, by increasing the particle size from 1 to $3 \mathrm{~mm}$, the total machine cost increased insignificantly from 2385.14 to 2388.03 L.E/Mg and 2364.39 to 2364.97 L.E/Mg for real hole diameters of 4 and5mm respectively, at die total thickness of $32.5 \mathrm{~mm}$, roller clearance of $2 \mathrm{~mm}$ and roller teeth width of $8 \mathrm{~mm}$. The obtained results showed that, the machine cost decreased from 2385.14 to $2374.00 \mathrm{~L} . \mathrm{E} / \mathrm{Mg}$ by increasing real hole diameter from 4 to $5 \mathrm{~mm}$ at particle size of $1 \mathrm{~mm}$, die total thickness of $32.5 \mathrm{~mm}$, roller clearance of $2 \mathrm{~mm}$ and roller teeth width of $8 \mathrm{~mm}$.This decrease may be attributed to the compressed ration take a less time to pass through die hole, that means increasing the productivity. On the other hand, the total cost increased by increasing dies total thickness and roller clearance. This increase could be attributed to the decrease of productivity, in addition to the increase in the consumed power to over come the compacting ration in larger clearances. Insignificant increase in cost per mass unit occurred by increasing the roller teeth width was observed. This is could be due to the low increase in the productivity and the low increase in power consumed. The values of total costs of 2386.58 and $2374.72 \mathrm{~L} . \mathrm{E} / \mathrm{Mg}$ for real hole diameter of 4 and $5 \mathrm{~mm}$ respectively, were recorded at the highest values of bulk density, pellet durability and pelleting efficiency using particle size of $1 \mathrm{~mm}$, die total thickness of $32.5 \mathrm{~mm}$, roller clearance of $2 \mathrm{~mm}$ and roller teeth width of $8 \mathrm{~mm}$.

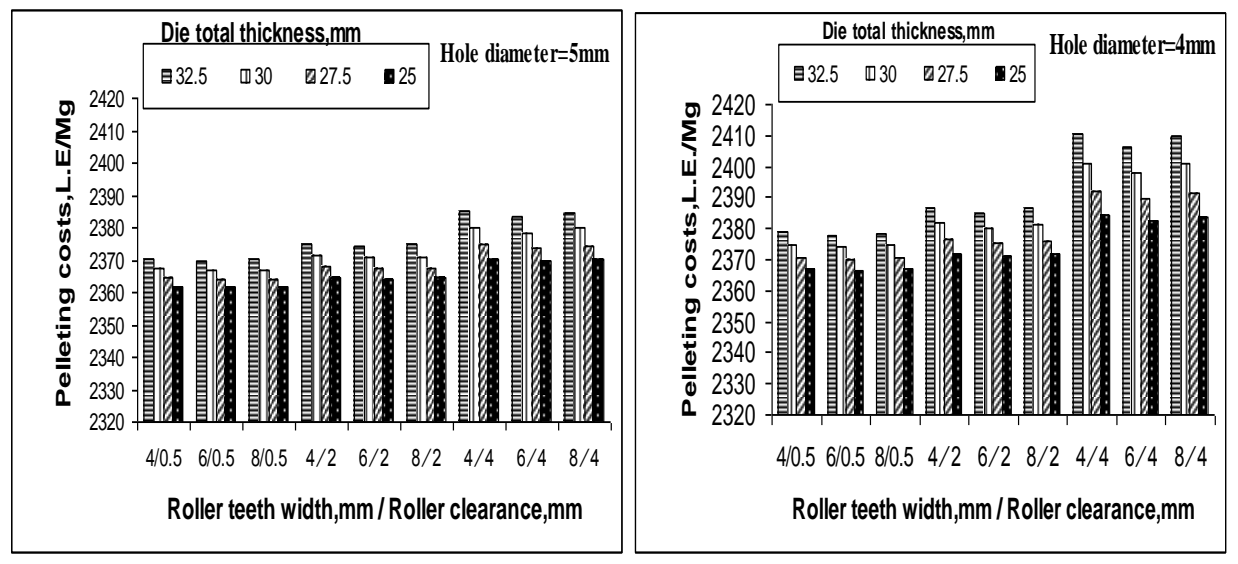

Fig.(8): Effect of some operating parameters on pelleting total costs at particle size of $1 \mathrm{~mm}$. 


\section{CONCLUSION}

It is recommended to operate the flat-die pelleting machine using particle size of $1 \mathrm{~mm}$, die total thickness of $32.5 \mathrm{~mm}$, roller clearance of $2 \mathrm{~mm}$, roller teeth width of $8 \mathrm{~mm}$ and real hole diameter of $4 \mathrm{~mm}$ to achieve the highest values of bulk density of $0.915 \mathrm{~g} / \mathrm{cm}^{3}$, pellet durability of $95.38 \%$,pelleting efficiency of $95.56 \%$, and pellet water stability of $70 \%$ (up to 4 minutes in water) with values of production rate of $107.10 \mathrm{~kg} / \mathrm{h}$, required energy of $97.95 \mathrm{~kW} . \mathrm{h} / \mathrm{Mg}$ and total cost of $2386.58 \mathrm{~L} . \mathrm{E} . / \mathrm{Mg}$.The highest values of bulk density of $0.850 \mathrm{~g} / \mathrm{cm}^{3}$, pellet durability of $91.65 \%$,pelleting efficiency of $94.84 \%$, and pellet water stability of $60 \%$ (up to $4 \mathrm{~min}$. in water) were recorded at real hole diameter of $5 \mathrm{~mm}$ with production rate of $143.65 \mathrm{~kg} / \mathrm{h}$, required energy of $58.41 \mathrm{~kW} . \mathrm{h} / \mathrm{Mg}$ and total cost of 2374.72 L.E./ Mg.

\section{REFERENCES}

ASAE. 1996. American society of Agricultural Engineers StandardsEngineering practices, and Data, ASAE standard book.

Awady, M.N., I. Yehia, M.T. Ebaid and E.M. Arif. 2003. Development and theory of rice cleaner for reduced impurities and losses. Misr J. Ag. Eng., 20(4) : 53-68.

Dec, R.T.1999. Selection of proper roll press operating parameters. Proceeding of the Institute for Briquetting and Agglomeration (IBA), 26:29-36.

Franke, M. and A. Rey. 2006 .Pelleting quality. World Grain:78-90.

Grover, P.D. and S.K. Mishra.1996. Biomass briquetting: technology andpractices. Regional Wood Energy Development Program in Asia, field document no. 46. Bangkok, Thailand: Food and Agriculture Organization of the United Nations (FAO).

Heinemans, H. 1991. The interaction of practical experience and the construction of new pelleting and cooling machinery. Advances in Feed Tech.,6:24-38.

Ibrahim, M. K. 1982. Wet milling of wheat grain. M. Sc. Thesis, Faculty of Agric., Mansoura Univ.,Egypt.

Obernberger, I. and G. Thek. 2004. Physical characterization and chemical composition of densified biomass fuels with regard to their combustion behavior. Biomass and Bioenergy : 27:653-69 
Thomas, M., D.J. van Zuilichem and A.F. van der Poel.1997. Physical quality of pelleted animal feed. 2. Contribution of processes and its conditions. Animal Feed Science and Technology, 64:173-192.

Turner , R.1995. Bottom line in feed processing: achieving optimum pellet quality. Feed Management;46:30-39.

\section{الملخص العربي}

العوامل المؤثرة علي أداءآلة تصبيع أعلاف الأسماك ذات المشكل المسطح

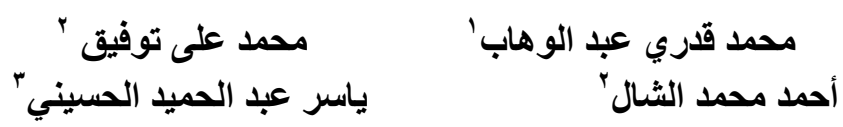

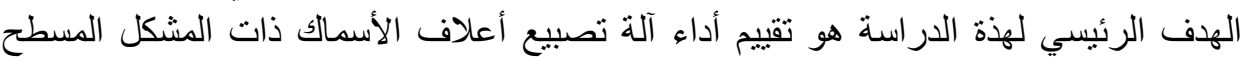

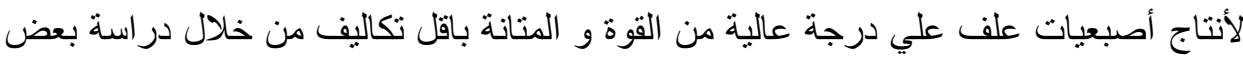

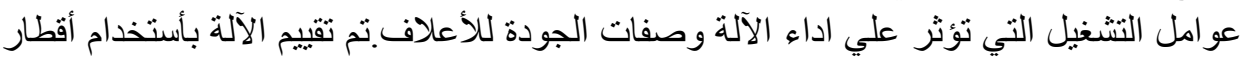

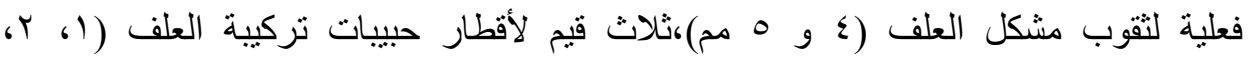

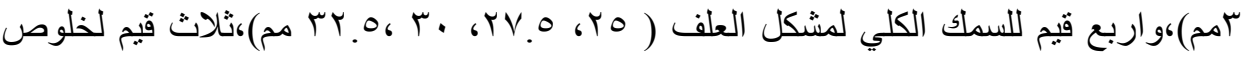

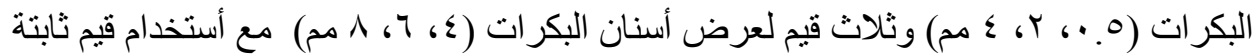

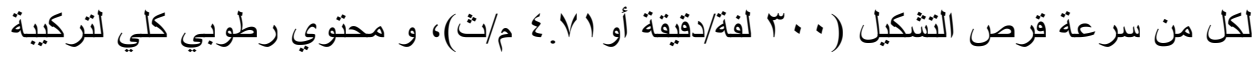

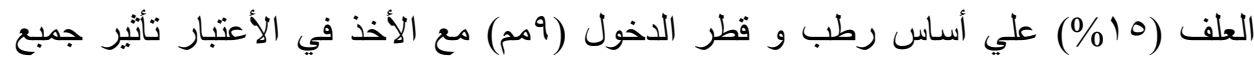

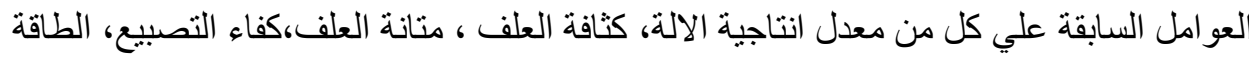

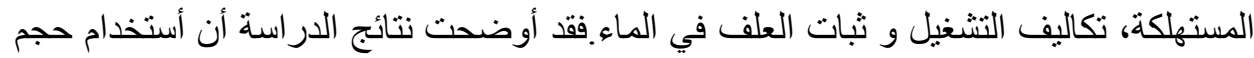

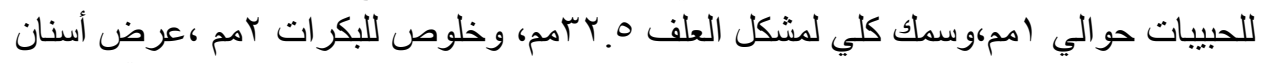

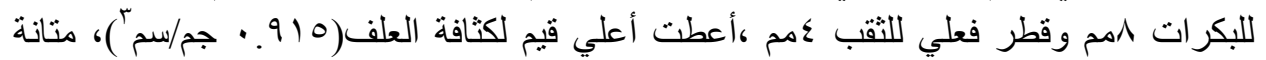

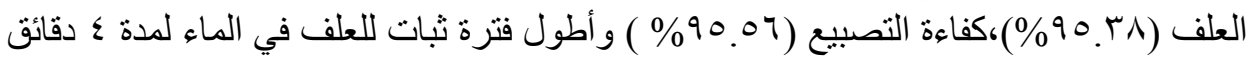

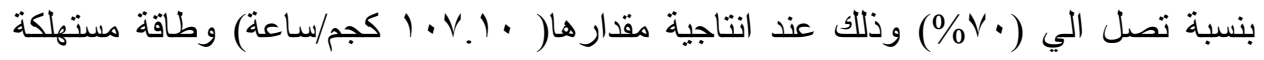

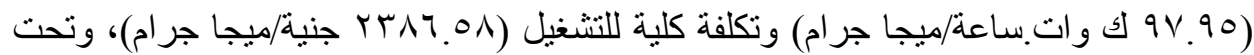

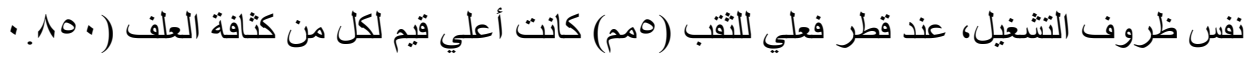

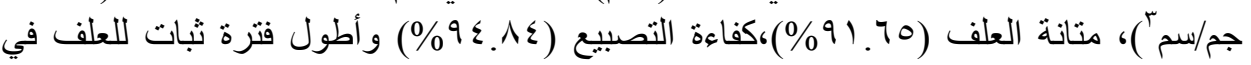
الماء بنسبة تصل الي (•r\%) قد تحققت وذللك عند انتاجية مقدارها (

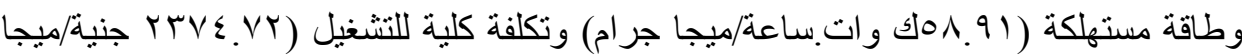

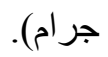

' 'أستاذ الهندسة الزراعية ـ كلية الزراعة - جامعة الزقازيق- مصر

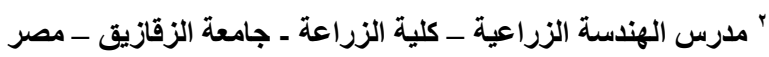

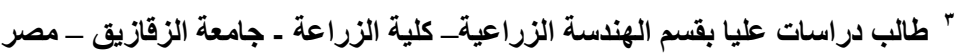

